\title{
EDYTA FEDORUSHKOV
}

\section{Атрофия разума: Юрьев день Кирилла Серебренникова}

\section{An atrophy of mind: Kirill Serebrennikov's St George's Day}

\begin{abstract}
The article analyses the figure of the heroine Lubov in Kirill Serebrennikov's film St George's Day. The main aim is to show how the town of Yuriev and its residents affect the spiritual change of Lubov. The author examines the consistent rejection of the truth of the mind in favour of the truth of faith in Lubov's life. The initial multilevel conflict between the opera singer and the town is supposed to be laid out in the Russian attitude to the world, which is based on the verge of two binary paradigms - the West and the East - exemplifying in turn the culture of the mind (reason) and the culture of faith (intuition). The provincial Russian town is correlated with the view of St. Petersburg in V. Toporov's 'Petersburg text' due to its particular and distinguishable influence on outer visitors: the town imposes on Lubov its rules, affecting her present life not only materially but most of all spiritually. Besides, the consecutive analyses allow to draw an analogy between Lubov and Dostoevsky's meek heroines. Like the 'humiliated and insulted' women of the author of Crime and punishment, the former opera singer enters the path of suffering and self-sacrifice to completely abandon her own self.
\end{abstract}

Keywords: reason, faith, intuition, St George's Day, new drama, Kirill Serebrennikov

Edyta Fedorushkov, Uniwersytet im. Adama Mickiewicza w Poznaniu, Poznań-Polska, edyszymk@ amu.edu.pl, ORCID ID: https://orcid.org/0000-0002-4260-5409

Русское мироощущение сформировалось на грани двух парадигм - западной и восточной, между культурами материи и духа, разума и чистейшей интуиции или, как пишет Михаил Эпштейн, „между ecmь и неm” (Èpštejn 118). Способ его существования в такой конфигурации можно определить как беспрестанно колеблющийся в зоне воздействия противоположных начал. Поскольку западная и восточная культуры сохраняют относительное внутреннее равновесие в пределах своих начал, постольку русская культура обречена на бесконечное сражение, которое вряд ли доведет одну из борющихся сторон к окончательной победе. Восходящий к петровской эпохе фундаментальный конфликт двух способов восприятия мира продолжается до настоящего времени, выливаясь в мировоззренческий диссонанс погруженной в этот мир личности. Именно с таким диссонансом, как можно полагать, 
мы имеем дело в художественной кинокартине Кирилла Серебренникова Юрьев день (2008).

Творческая деятельность российского режиссера не ограничивается лишь киноискусством, а охватывает такие виды зрелищного искусства, как театр или опера. Именно театральные постановки Серебренникова внесли значимую лепту в появление так называемой „новой драмы”, - течения, зародившегося в 1990-х гг., сначала в русле театрального движения, а со временем ставшего самым узнаваемым в современном российском кино. Следует отметить, что такой довольно плавный и естественный переход новых театральных тенденций в область кинематографии обязан не только личности режиссера, перенесшего театральный спектакль на экран, но прежде всего уникальным для нынешнего киноискусства стремлением к средствам художественной выразительности, значимо театрализующим заданный реализм кинополотен. Общим знаменателем для современного российского фильма и театра, как можно полагать, является именно драма - ситуация, проявляющаяся, как правило, в конфликтных взаимоотношениях между людьми, выраженных в словесно-физических действиях. Популярность этой восходящей к древней трагедии диалогической формы искусства можно приписать кризису, зарождающемуся при каждом столкновении несогласованных взглядов (голосов). Конфликт поколений, ценностей, социальных групп, мировоззрений или идеологий - это всегда межличностный конфликт, каждый раз побуждающий к действию, являющемуся, в свою очередь, сущностью драмы как таковой.

Вышеупомянутый мировоззренческий диссонанс, конкретизирующийся в многоуровневом межличностном конфликте, характерен именно для русского менталитета. Лихие девяностые, а затем нулевые наметили его следующую веху. „Новая драма” в сознании современного русского человека отозвалась, по словам Маи Меркуловой, „столкновением позиций самоопределений, самоидентификаций индивидуумов в процессе коммуникации", отчасти сместилась внутрь его подсознания (Merkulova 125). В кино данный сдвиг, как можно полагать, обозначен ярко экспонированным, хотя весьма неоднозначным местным ландшафтом, служащим точкой отсчета для внутреннего конфликта личности героя. Союз человеческой драмы с так называемой „чернухой”, эпатирующей и изобилующей темными сторонами жизни и быта современного русского общества, оказался благоприятной и плодотворной почвой, чтобы задать важные экзистенциальные вопросы.

Героиня кинополотна Кирилла Серебренникова - Любовь Павловна, оперная дива, приезжает в город Юрьев-Подольский с целью ознакомить сына с родными местами перед отъездом в Германию. К ностальгическому 
путешествию матери в прошлое подрастающий Андрей относится с явным неудовольствием. Город неприветлив, что подчеркивают не только зимние пейзажи, но также холодное обращение его жителей с приезжими. Однако это не останавливает переполненную ностальгией Любовь Павловну перед посещением очередных мест на карте памяти, несмотря на их полностью изменившийся облик в действительности. Героиня разрешает Андрею самостоятельно посетить выставку в городском музее, а сама невольно задремывает на скамейке. После пробуждения она обнаруживает, что Андрея нигде нет. Любовь Павловна остается в городе и ищет сына.

Следует отметить, что узловые вопросы, касающиеся многоуровневой семантики фильма, поднимались уже другими учеными. Особенной активностью в этом плане отличается исследовательская деятельность Светланы Орищенко. В своих работах киновед раскрывает основные культурные, языковые, речевые метафоры фильма, опираясь на набор общекультурных кодов: библейских мотивов, народных традиций, исторических событий, литературных реминисценций и др. (Oriŝenko 2012a, 2012b, 2012c).

Само путешествие матери с сыном, которое можем прочитывать как своеобразную прелюдию к главному сюжету фильма, ознаменовано контрастом. По занесенному снегом пустому шоссе несется машина, иномарка. Внутри машины ведется монолог: женщина за рулем довольно бурно объясняет чтото своему незаинтересованному сыну, но зрителю доступна лишь ее резкая жестикуляция. Звуковым фоном для данной сцены служит оперная ария, исполняемая (о чем мы узнаем несколько времени спустя) главной героиней. Драматичному, хотя упорядоченному в своей музыкальной аранжировке, пению противопоставляется хаотичная скрипичная (и скрипучая) композиция, включенная сыном. Этот музыкальный диссонанс намечает основной конфликт фильма - конфликт несогласованных позиций (необязательно односторонне приписываемых персонажам матери и сына).

Сохраненный героиней с детства светлый образ родного места растворяется в момент приезда в город: Юрьев затянут туманом, а произнесенные про себя слова Любови: „Кажется, здесь” - подтверждают ее некоторую неуверенность относительно правильности местонахождения. Возникающий из тумана шлагбаум с дорожным знаком „движение запрещено” служит очевидным символом. Город назначает тем самым границу, границу мира, в котором привыкла жить Любовь. Хотя детство Любови прошло в провинциальном городке, ее взрослая жизнь связана с большим городом. Именно там Любовь добилась успеха, что и поспособствовало принятию другого образа жизни. Поэтому путешествующая на дорогой западной машине певица здесь уже не „своя”, она чужая. Она живет в цивилизованной большой Москве, которую с западноевропейским миром разделяет лишь несколько часов 
пути. Чтобы пересечь границу и войти в Юрьев, Любовь обязана покинуть свою машину, атрибут состоятельности и жизненного удобства.

Так намеченное разногласие двух разных топосов, как можно полагать, отсылает к берущей свои корни в славянофильских трактовках антиномии двух миров - России и Европы, элементов восточного и западного миров. Отличительность и специфика культурного наследия, а также разный исторический опыт России (во всех ее государственных проявлениях) и стран Западной Европы способствовали образованию конфликтогенной оппозиции Восток - Запад. Разумный, рассудочный, аристотелевский, католическо-протестантский Запад в славянофильской мысли противопоставлен идеализированной интуитивной, духовной, платонической и православной России. Вероятно, эту упрощенную схему бинарного мышления можно обнаружить во временном мироощущении героини в момент ее путешествия в родной городок. Однако запечатленное в памяти счастливое время детства, проведенное в теснейшей связи с природой, оказывается лишь ностальгической сказкой, выдумкой, чудящейся в воображении Любови. Несмотря на искреннее желание возвращения „на минуту” домой, на свою малую родину, героиня встречена Юрьевым весьма неприветливо. Местные жители обходят молчанием вопрос Любови о названии речки. Родной дом превращен в рюмочную. Кремлевский музей открывается только по просьбе редких посетителей (желательно приобретших футболку-сувенир с медведем). Можно заметить, что попытка Любови логически связать прошлое с настоящим в духе культурно-цивилизационного прогресса проваливается. Скованная льдом речка ведь не течет (по крайней мере, подводное течение незаметно простым глазом), атмосфера рюмочной ничем не напоминает домашнего уюта или хотя бы стилизованных современных рюмочных, приятных мест, где можно посидеть и вкусно поесть, а, скорее, наводит на мысль о предназначенных исключительно для мужчин неприглядных заведениях. В отличие от подвигающейся вперед эмансипации женщин в западном обществе, нравы здешней общественности, как можно полагать, застряли в патриархальном прошлом. Также музей, „храм музы”, а следовательно, и храм искусства, с культурно-научной и воспитательной функциями, занимает последнее место в рейтинге человеческих потребностей. За ним присматривают местные „униженные и оскорбленные”: одна женщина с мутным взглядом, вторая - хромоножка и третья - выпивающая и битая братом Татьяна; все три с волосами, покрашенными оранжеватой, единственно доступной в Юрьеве краской, хной.

Любовь, кажется, не замечает того, что видит сын. Для героини фильма Юрьев представляет собой квинтэссенцию родины, русской земли, чему материальным доказательством, по словам Любови, служит хотя бы наличие 
здесь плодородного чернозема. Однако если изучить символическую значимость и влияние чернозема на жизнь Любови, окажется, что его плоды не так уж урожайны. Сын Андрей не заинтересован городком, более того, его отношение к матери явно пренебрежительно. Однодневная поездка не в силах наладить отношения матери с сыном, как и не сможет принести певице с мировым именем чувства духовного удовлетворения.

Столкновение разных позиций или, говоря словами Бахтина, голосов, как ожидаемых, так и тех неожиданных, наводит на мысль об особой роли города Юрьев как центра самопознания. Заметно экспонированная в фильме субъектность Юрьева позволяет рассматривать отношения с городом (и, скорее всего, его жителями) в характере своеобразного диалога, направленного на самоопределение личности. Невольно здесь возникает ассоциация с Петербургом, а, вернее, с петербургским текстом как творением не столько языковым, сколько духовным, экзистенциальным, поднимающим вопросы, „касающиеся сферы мифов, символов, архетипов, следовательно, высшего класса универсальных способов проявления бытия в знаке” (Żyłko 10). Причем отмеченная нами аналогия не основана на архитектурном или культурном подобии Юрьева и Петербурга. Сходство этих двух городов обнаруживается в плане их особого воздействия на перешагивающую их границу личность. Особенно значимым для нашей интерпретации Юрьева сквозь призму петербургского текста является его устройство, с помощью которого, как пишет Владимир Топоров, „совершается переход a realibus ad realiora, от видимой реальности и через нее к более реальной реальности, т. е. пресуществление материальной реальности в духовные ценности” (Toporov 7).

Такой путь город Юрьев назначает Любови (хоть и вопреки ее разумной воле). В первое время ностальгический восторг у Любови вызывают материальные и чувственные признаки города: певица восхищается запахом жаренной на комбижире капусты, ее ошеломляет вид из кремлевской башни с шатровым завершением, гордость за малую родину вселяет в нее наличие здесь плодородного чернозема. Одновременно заметно, что приезжая - единственный человек в городе, который признает его запустение очаровательным. Характерна в этом плане именно сцена в кремлевской башне. Пораженная бескрайним простором Любовь декламирует маленький фрагмент из поэмы Александра Блока На поле Куликовом, а затем актерски вскрикивает чеховское „я - чайка”. Раскинутые, как крылья, руки могут свидетельствовать о сильной потребности в свободе, которая как раз и осуществляется, хотя ее реплика „Как привольно!” в сценарии Юрия Арабова (Arabov, электронный ресурс) заменена на „Ты посмотри, какая красота!” в фильме. Однако следует заметить, что ощущаемое Любовью в тот момент чувство свободы мнимо или - иначе - разумно. Как пишет Топоров, 
свобода [может пониматься] безрелигиозно - как разумный (точнее, рассудочный), логикой, примерами и аналогиями поддержанный, прагматически-утилитарный выбор между двумя или более в принципе равноудаленными от того, что „правильно”, „нужно”, „полезно", предметами выбора. [...] Но есть и принципиально иное понимание свободы, при котором она оказывается ориентированной на сугубо внутреннее движение души и выступает как свое собственное усиление. Речь идет уже не столько о свободе выбора свободы, сколько о свободе представления этого выбора самой судьбе, то есть об отказе от „собственного” выбора со стороны Я, о свободе выхода за пределы пространства, в котором возможность выбора понимается как признак свободы (Toporov 284-285).

Как можно полагать, судьба героини фильма до сих пор строилась на ее последовательном, разумном и утилитарном выборе, совершаемом, впрочем, по соображениям собственного пристрастия и удовлетворения. Выезд из Юрьева в столичный город позволил Любови проявить себя, но желание добиться успеха оказалось для нее важнее личного и семейного счастья. Приезд в Юрьев и глоток „свободы” не является для героини самоцелью, а лишь не совсем понятной кратковременной остановкой на пути к Западной Европе. Интересно, что в Юрьеве в поведении героини угадывается некоторая неловкость. Оперная дива ведет себя так, будто она выступает на сцене - манерно и помпезно. Актерскую установку подчеркивает сцена, в которой Любовь перед въездом в город смотрится в стекло машины, подправляя несколько раз посадку шапки, что напоминает приготовления актрисы перед выходом на оперную сцену. Динамичная и экспрессивная жестикуляция героини во время пребывания в Юрьеве, с одной стороны, свидетельствует о ее отточенном актерском мастерстве, с другой же стороны, возможно, она есть выражение нервной реакции на встречу с давно не виденным городом. Театральность поведения Любови заметна также в ее отношениях с сыном. Большинство его реплик героиня игнорирует, будто играя спектакль одного актера.

Этот спектакль одного актера заканчивается в момент загадочного исчезновения сына. Симптоматичен в этом плане момент пробуждения героини на скамейке, которому предшествует появившийся на несколько секунд черный экран. Данный прием напоминает спуск занавеса, отмечающий конец спектакля. Последующее за ним зрелище, как можно полагать, открывает подлинную драму - драму жизни.

Медленный и размеренный ход камеры меняется порывистыми и хаотичными рывками, будто копирующими беспокойные и суетливые движения Любови. Иногда зритель может вынести впечатление, что имеет дело с репортерским жанром, нежели с художественным кинополотном. Данный прием, возможно, задается целью ,разрегулировать” зрительское ожидание и закономерность хода событий. Этой дезорганизации соответствует поведение Любови. Наигранные, сценические движения героини (особенно яркий 
и многозначительный момент, когда Любовь патетично притаптывает снег на мосту, не замечая лежащее под ним тело погибшей птицы), теряют свою продуманность. Правда, певица передвигается по траектории потенциального пути, пройденного сыном, однако с каждой истекшей минутой рассудительность ее действий ослабевает. Первоначально зритель замечает это на материальном уровне. Свой телефон, атрибут связи с „миром” (последний звонок принят из Германии), случайно роняет в свежевылитый асфальт. Меховую шапку она меняет на шерстяной платок, а дорогую шубу на - как сама раньше о нем высказалась - „правдивый, как хлеб, солженицынский ватник”. Можно сформулировать мысль, что героиня фильма последовательно раздевается, сбрасывая с себя слои того мира, из которого прибыла. Телефон не сможет связать (соединить) ее с сыном, меховая шапка не убедит милиционера на службе тотчас же заняться исчезновением Андрюши, равно как и пышная шуба не принудит местных жителей к особому отношению к даме из Москвы. Угрозы певицы, посылаемые в адрес не желающих ей помогать жителей, бесполезны и напрасны; местные говорят: „Здесь нечего разрушать". Город передает героине ясное сообщение: все меры и средства, предпринимаемые в большом городе, здесь теряют свою значимость. Путь разумного развития, намечаемый удовлетворением материальных в основном потребностей общества, сюда не доходит. Юрьев будто заколдован, о чем, кажется, сигнализирует зловещий образ возникшей из тумана женщины, катящей перед собой коляску, в начале фильма. Чтобы отыскать сына, Любовь вынуждена отречься от самой себя, от привычных для нее устоев, от жизни „внешнего человека”. В конце концов, свою гордость и независимость Любовь обязана принести в жертву. Именно это поможет ей отыскать саму себя и спасти свою душу.

Нетрудно здесь заметить некоторую аналогию между героиней фильма и жертвенными героинями Федора Достоевского. Подобно кротким женщинам, Любовь словно спускается в ад провинциальной жизни, вступает на путь страдания и самопожертвования, становясь одной из „униженных и оскорбленных". Выпивая с приютившей ее Татьяной, отдавая свое тело в наслаждение местному мужчине, окончательно нанимаясь в уборщицы в самом мерзком месте в городе, тюремной туберкулезной больнице, Любовь невольно подчиняется жестоким правилам здешней жизни. Характерен в этом плане эпизод, в котором певица не может выдавить из себя слова. Потеря голоса лишает ее возможности высказать свою волю, ответить репликой, полемизировать или же быть услышанной. Данный момент, как можно полагать, символически позволяет перешагнуть Любови на ту сторону „свободы”, т. е. свободы „как отказа от собственного выбора со стороны Я”, „свободы выхода за пределы пространства, в котором возможность выбора 
понимается как признак свободы". Такую трактовку подтверждает сцена, в которой Любовь видит себя на экране телевизора. Ту женщину, оперную диву, Любовь отвергает и становится Люсей, женщиной, некогда жившей в Юрьеве и опознанной местным мужчиной Серым.

Законы разума, руководящие волей Любови, ослабевают во время нескольких опознаний сына. Удивительное и необъяснимое сходство между исчезнувшим Андреем и тремя его сверстниками искажают способность к разумной оценке ситуации. Интересно, что каждый следующий опознаваемый юноша становится чем-то похож на ее сына. У одного, мальчика-утопленника, были такие же резиновые сапоги, как у сына; другой, послушник в монастыре, тоже Андрей из Москвы; третий, малолетний уголовник, подобно сыну Андрею, принадлежит к тому небольшому проценту людей, которые не хотят водить машину. Слова болеющего туберкулезом молодого мужчины, как можно полагать, дополняют перемену в главной героине, которая в символической сцене омовения окровавленного тела заключенного становится его матерью. Выбор героини довольно очевиден: Любовь отвергает „правду разума” в пользу „правды веры”. Последствия такого выбора захватывают не только ее. Все трое мужчин в каком-то смысле мертвы: первый - утопленник, второй ушел из мирской жизни, что для светской семьи равносильно его смерти. Третий, уголовник, смертельно болен. Однако не физическая болезнь угрожает его жизни. У него нет матери, и Любовь, заменяя ему мать, спасает его духовную жизнь.

Следует здесь отметить, что путь, пройденный главной героиней, отчасти напоминает процесс деификации, т. е. обожения. О популярной в кругу православных неоплатоников мысли можем прочитать в книге Рышарда Пшибыльского Достоевский и ,проклятые проблемы” ” следующее:

Деификация (обожение) возможна только после выхода из сферы знания. Божий уровень бытия можно достичь благодаря благодати познания Бога, однако при условии, что человек прекратит „добиваться вещей этого [земного] мира”, что отречется от мудрствования и отодвинет от себя размышления разума. Самым достоверным путем обожения души являются аскетические практики и мистическая контемпляция, которую рекомендовал исихазм монахов из Святой Горы Афон (Przybylski 163 - пер. Э.Ф.).

По нашему наблюдению, участь героини фильма роднит ее с героями Достоевского. Как пишет Пшибыльски,

Для Достоевского самопожертвование - это борьба с собственной природой, это страдание, благодаря которому человек включается в процесс деификации (обожения) и таким образом удерживает мир в моральном равновесии, придает ему смысл (Przybylski 170 - пер. Э.Ф.). 
Переходя на высший уровень интерпретации фильма, нетрудно заметить также признаки-символы христианского происхождения, придающие особый смысл обыкновенным, на первый взгляд, явлениям. Так, горящие новогодние елки однозначно наводят на мысль о библейской неопалимой купине, несгорающем терновом кусте, в котором Бог явился Моисею. Любовь бежит за звуком, который приводит ее именно ко двору, в котором сжигаются елки. Одновременно Любовь опознает источник звука. Им оказывается телевизор, в котором поет оперная певица. Это совмещение двух уровней ее существования - земного и мистического (духовного) - можем считать залогом ее духовного роста: горящий куст, призвавший Любовь, можно интерпретировать как нисхождение божьей благодати, мистическое прозрение, которого не могла достичь героиня во время исполнения оперного концерта.

Многозначна в этом плане последняя сцена фильма. Чтобы быть принятой в церковный хор, Любовь вынуждена подчиниться, следовательно, отказаться от сольного выступления, к которому привыкла на больших, светских и торжественных концертах. Этот символический жест героиня исполняет еще до того, как войти в церковь. С покрашенными, как у всех женщин в Юрьеве, оранжеватой краской волосами певица прикасается головой к Татьяне. Причину этому Любовь не ищет, не пытается ответить на вопросы, которыми задается зритель фильма. Ее духовное воскресение, согласно учению Отцов Церкви, происходит в ее душе, в сердце, без участия разума, т. е. непроизвольно и бессознательно.

\section{Библиография}

Arabov, Ûrij. Ûr'ev den'. Scenarij. Web. 18.03.2020. http://old.kinoart.ru/archive/2008/05/n5article19

Èpštejn, Mihail. Postmodern v russkoj literature. Moskva, Vysšaâ škola, 2005.

Merkulova, Majâ. „Novaâ drama”. Novyj filologičeskij vestnik, 2 (17), 2011, s. 122-126.

Oriŝenko, Svetlana. „Hudožestvennyj fil'm $\hat{U} r^{\prime} e v$ den' Kirilla Serebrennikova v kontekste semantiki i metafiziki goroda". Izvestiâ Samarskogo naučnogo centra Rossijskoj akademii nauk, 14, 2012a, s. 1017-1023.

Oriŝenko, Svetlana. „Metafory fil'ma $\hat{U} r^{\prime} e v$ den' Kirilla Serebrennikova”. Izvestiâ Samarskogo naučnogo centra Rossijskoj akademii nauk, 14, 2012b, s. 1283-1289.

Oriŝenko, Svetlana. „Čehovskie motivy v fil'me Kirilla Serebrennikova Ur'ev den". Izvestiâ Samarskogo naučnogo centra Rossijskoj akademii nauk, 14, 2012c, s. 1553-1559.

Przybylski, Ryszard. Dostojewski i „przeklęte problemy”. Warszawa, Sic!, 2010.

Toporov, Vladimir. Peterburgskij tekst russkoj literatury. Sankt-Peterburg, Iskusstvo SPB, 2003.

Żyłko, Bogusław. „Słowo wstępne”. Władimir Toporow, Przestrzeń i rzecz. Kraków, Universitas, 2003, s. 5-14. 